\title{
PROSES PENANGKAPAN DAN TINGKAH LAKU IKAN BAGAN PETE PETE MENGGUNAKAN LAMPU LED
}

\section{CAPTURE PROCESS AND FISH BEHAVIOR ON BOAT LIFT NET USING LED LIGHTS}

\author{
Salman', Muhammad Sulaiman ${ }^{1}$, Sultan Alam ${ }^{1}$, Anwar $^{2}$, Syarifuddin $^{3}$ \\ ${ }^{1}$ Politeknik Pertanian Negeri Pangkep, Pangkep \\ ${ }^{2}$ Laboran Navigasi, Politeknik Pertanian Negeri Pangkep, Pangkep \\ ${ }^{3}$ Laboran Kapal Latih, Politeknik Pertanian Negeri Pangkep, Pangkep \\ Korespondensi : dgcule1@gmail.com
}

\begin{abstract}
Concept of research activity and development of fishing technology in the future is not only aimed to improve the catch but is also aimed to improve the capture process, reducing the impact of fishing on the environment and biodiversity. The research was conducted with the purpose of the analysis stage of the operation and problems in operating the lift net (bagan pete pete) typical South Sulawesi especially Barru Regency and inputs to the tactics and methods of fishing, through: analyze stage of the operation and analyze the patterns of fish behavior around lighting on the boat lift net (bagan pete pete) by using LED light. This study was conducted in in Barru District waters, Strait of Makassar, South Sulawesi. Field observations were conducted from June-August 2014 (20 trips). Analysis of the fishing was done descriptively to see the stages of operation, while fish behavior was observed by using fish finder. Stages of operation bagan petepete was preparation operation, heading fishing ground, the lighting process, setting, soaking, the process of extinguishing the lights, hauling, taking the catch, and the process of appointment of waring to the boat. Fish shoal approached the light was at a depth of 5-10 $\mathrm{m}$ and 20-30 $\mathrm{m}$ from any directions after all the lights turned on. When only one lamp lit on each side, the shoal was getting smaller but in larger density.
\end{abstract}

Keywords: capture process, fish behavior, Light Emitting Diode, lift net

\begin{abstract}
ABSTRAK
Konsep aktivitas penelitian dan pengembangan teknologi penangkapan ikan pada masa yang akan datang tidak hanya ditujukan meningkatkan hasil tangkapan tetapi juga ditujukan untuk memperbaiki proses penangkapan (capture process), mengurangi fishing impact terhadap lingkungan dan biodiversitas. Penelitian dilakukan dengan tujuan untuk menganalisis tahapan pengoperasian dan permasalahan dalam mengoperasikan lift net (bagan pete pete) khas masyarakat Sulawesi Selatan khususnya Kabupaten Barru dan masukan terhadap taktik dan metode penangkapan ikan, melalui: analisis tahap proses pengoperasian dan analisis tingkah laku ikan di sekitar pencahayaan pada bagan petepete (boat lift net) yang menggunakan lampu LED. Penelitian ini dilaksanakan di perairan Kabupaten Barru-Selat Makassar, Sulawesi Selatan. Pengamatan lapang dilakukan dari bulan Juni sampai Agustus 2014 (20 trip). Analisis deskriptif dilakukan untuk melihat tahapan operasi penangkapan, sedangkan pengamatan tingkah laku ikan diamati dengan menggunakan fish finder. Tahapan pengoperasian bagan petepete adalah: persiapan operasi, menuju fishing ground, proses penyalaan lampu, proses penurunan waring (setting), proses menunggu kawanan ikan (soaking), proses pemadaman lampu, proses pengangkatan waring (hauling), pengambilan hasil tangkapan, dan proses pengangkatan waring ke atas bagan. Analisis tingkah laku ikan memperlihatkan pola pergerakan kawanan ikan mendatangi pencahayaan berada pada kedalaman 5-10 m dan 20-40 m dari segala arah pada saat semua lampu dinyalakan. Pola kawanan ikan terkonsentrasi di sekitar catchable area pada saat hanya satu lampu yang dinyalakan di setiap sisi dengan jumlah kawanan semakin sedikit tetapi kepadatan kawanan yang besar disebabkan bergabungnya beberapa kawanan ikan sehingga kawanan ikan semakin membesar.
\end{abstract}

Kata kunci: jaring angkat, Light Emitting Diode, proses penangkapan, tingkah laku ikan 


\section{PENDAHULUAN}

Bagan berdasarkan pengoperasiannya dapat dikelompokkan ke dalam jaring angkat atau lift net (Von Brand 2005). Bagan dapat diklasifikasikan ke dalam beberapa kelompok, berdasarkan mobilitasnya, maka dikenal bagan tancap dan bagan apung. Bagan tancap sifatnya menetap, sedangkan bagan apung dapat berpindah dari satu fishing ground ke fishing ground lainnya. Bagan apung berdasarkan alat pengapungnya juga dapat dibagi dua yaitu yang menggunakan perahu dan alat apung lainnya (rakit atau drum). Bagan petepete merupakan bagan apung dengan mobilitas tinggi yang menggunakan perahu sebagai alat pengapungnya dan memiliki mesin penggerak sendiri sehingga sering pula disebut dengan bagan petepete (sejenis angkot di Kota Makassar).

Pengoperasian bagan petepete menggunakan lampu merkuri dengan kapasitas watt yang besar dan populer digunakan nelayan bagan di Sulawesi Selatan. Berdasarkan hal tersebut maka perlu dicari alternatif lampu merkuri yang lebih efektif dan efisien. Salah satu alternatif adalah mengganti dengan menggunakan lampu Light Emitting Diode (LED). Penggunaan lampu LED semikonduktor telah diakui sebagai cara penting untuk penghematan energi dan perlindungan lingkungan (Hua \& Xing 2013).

Penelitian tentang pemanfaatan lampu LED dalam bidang penangkapan ikan belum banyak dilakukan. Beberapa peneliti yang telah melakukan penelitian tentang lampu LED dibidang penangkapan ikan antara lain: Sato et al. (2010) dan Yamashita et al. (2012) mencoba kemampuan tangkap kapal cumi (squid jigger) yang menggunakan panel lampu LED dan dikombinasikan dengan lampu metal halide, Inada et al. (2010) meneliti tentang aplikasi LED untuk perikanan industri, ekologis dan ekonomi dalam penangkapan ikan dengan menggunakan cahaya, Okamoto et al. (2008) dan Toeda et al. (2010) meneliti tentang aplikasi LED pada penangkapan ikan sauri Pasifik.

Adopsi teknologi dari penggunaan lampu merkuri diganti dengan lampu LED memerlukan percobaan dan penelitian karena sifat dan karakteristik lampu yang digunakan sebagai pengumpul ikan berbeda. Perbedaan itu antara lain, lampu LED dapat diredupkan sedangkan lampu merkuri tidak. Lampu LED sifat pencahayaannya fokus sedangkan lampu merkuri lebih berpendar walaupun sudah menggunakan penutup lampu (tudung pabrikasi).

Pengetahuan lain yang perlu diketahui adalah tingkah laku ikan karena prinsip penangkapan bagan pada dasarnya memanfaatkan tingkah laku ikan, khususnya respon ikan terhadap cahaya. Pengamatan bawah air tergolong pengamatan yang sulit sehingga dalam penelitian ini pengamatan tingkah laku ikan di sekitar pencahayaan dilakukan melalui pendekatan akustik.

Tujuan dari penelitian ini adalah menganalisis sistem pengoperasian dan tingkah laku ikan bagan petepete yang menggunakan lampu LED sebagai alat bantu penangkapan ikan. Diharapkan dari penelitian ini diperoleh informasi ilmiah tentang efektivitas lampu sebagai alat bantu penangkapan ikan dalam perikanan light fishing.

\section{METODE PENELITIAN}

Pengukuran intensitas dan distribusi cahaya lampu merkuri dan LED dilaksanakan di Workshop Simulasi dan Navigasi Politeknik Pertanian Negeri Pangkep. Proses penangkapan ikan dengan menggunakan alat bantu penangkapan ikan dari lampu mekuri dan LED dilakukan di perairan Kabupaten Barru-Selat Makassar, Sulawesi Selatan. Lokasi pengamatan terletak pada posisi $4^{\circ} 27.5^{\prime}-4^{\circ} 30.5^{\prime}$ LS dan $119^{\circ} 31.5^{\prime}-119^{\circ} 33.5^{\prime}$ BT (Gambar 1). Pengamatan lapang dilakukan selama 20 trip penangkapan pada bulan Juli sampai Agustus 2014.

Bagan yang digunakan dalam penelitian ini adalah bagan yang berada di Kabupaten Barru yang dikenal sebagai bagan petepete oleh nelayan di Sulawesi Selatan. Bagan pete pete dilengkapi lampu LED sebagai alat bantu penangkapan ikan, fish finder $160 \mathrm{C}$ (Garmin, frekuensi 50 dan $200 \mathrm{kHz}$ ), dan GPS (Garmin $76 \mathrm{CX}$ ) untuk posisi lokasi penangkapan.

Satu unit bagan petepete terdiri atas beberapa komponen utama yang saling terkait satu sama lain. Komponen tersebut adalah: perahu, rangka, waring, bingkai waring, roller, generator set (genset), lampu LED, dan rumah bagan yang berukuran 25 × 25 m, kamera digital (Canon G12) digunakan untuk merekam semua kegiatan selama penelitian. Kamera juga digunakan untuk menyimpan hasil tampilan monitor fish finder selama penelitian. Alat yang digunakan selama penelitian dapat dilihat 
pada Gambar 2.

\section{Analisis proses penangkapan}

Analisis proses penangkapan dilakukan secara deskriptif untuk melihat tahapan kegiatan operasi dan menghitung waktu yang dibutuhkan untuk setiap tahap kegiatan. Data tersebut digunakan untuk membuat diagram proses penangkapan.

\section{Analisis tingkah laku ikan}

Observasi tingkah laku ikan pada bagan petepete dilakukan dengan pengamatan secara visual di permukaan air. Pengamatan di kolom perairan dilakukan dengan menggunakan fish finder.

Pola distribusi kawanan ikan di sekitar pencahayaan sebelum dan setelah proses penangkapan, pola kedatangan kawanan ikan di sekitar pencahayaan dan tingkah laku ikan di sekitar pencahayaan yang meliputi pola pergerakan di sekitar pencahayaan dianalisis secara deskriptif berdasarkan hasil pengamatan visual dan rekaman fish finder.

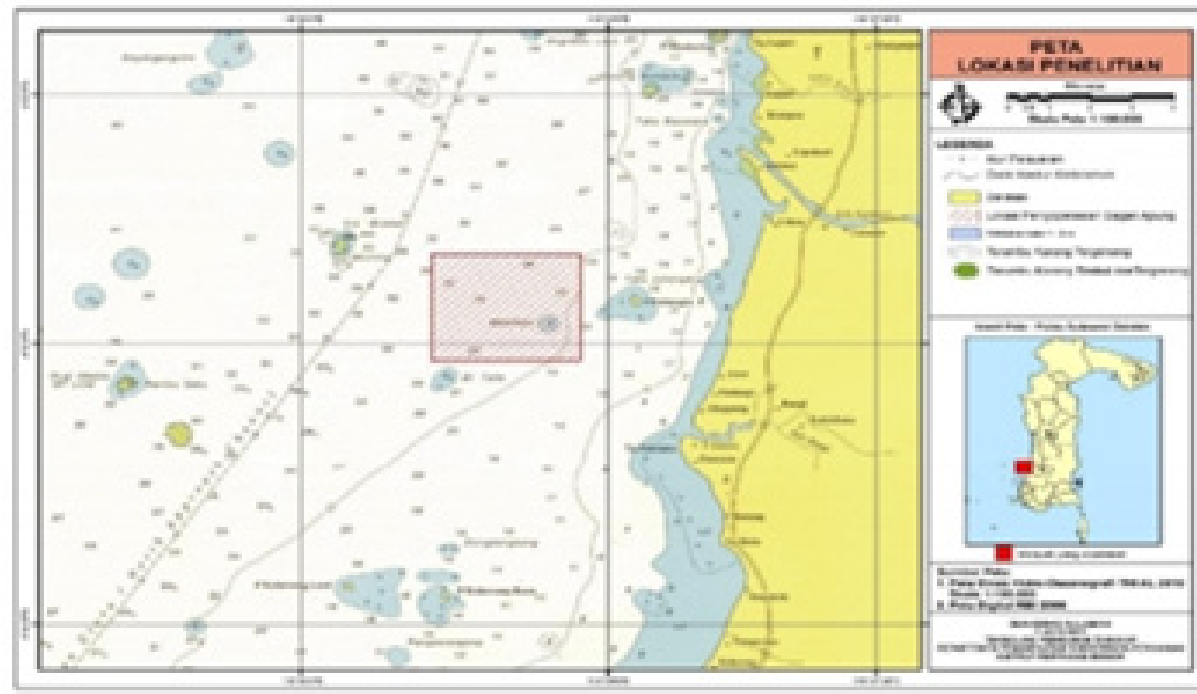

Gambar 1. Peta lokasi penelitian di perairan Barru Selat Makassar

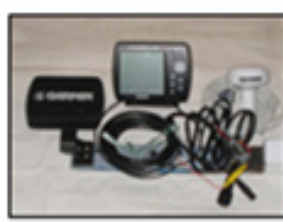

A

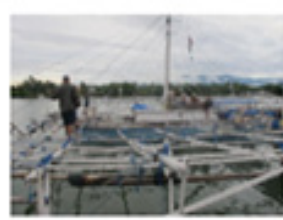

B

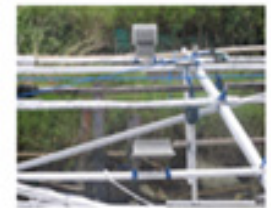

C

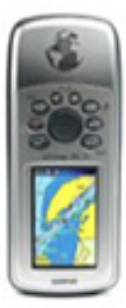

D

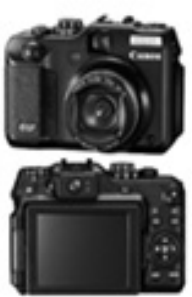

E

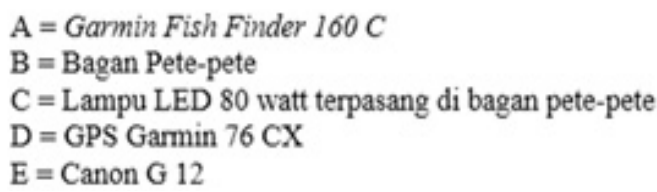

Gambar 2. Alat yang digunakan selama penelitian 


\section{HASIL DAN PEMBAHASAN}

\section{Proses penangkapan bagan pete pete}

Pengoperasian bagan petepete membutuhkan 9 sampai 13 orang anak buah kapal (ABK) yang dipimpin oleh seorang juragan laut atau disebut dengan punggawa laut dan dibantu seorang bass yang bertanggung jawab terhadap mesin penggerak dan genset serta membantu memutar roller, menggiring ikan dan mengangkat ikan ke atas kapal. Juragan laut memimpin dan bertanggung jawab penuh terhadap seluruh operasi penangkapan ikan. Tugas lain dari punggawa laut yaitu: mengatur pencahayaan lampu dan mengatur tali jangkar pada saat hauling. Tugas $12 \mathrm{ABK}$ yaitu memutar roller dan menggiring ikan pada salah satu sisi bagan yang berfungsi sebagai kantong serta menaikkan ikan ke atas kapal.

Tahapan pengoperasian bagan pete pete:

1. Persiapan operasi. Proses pengoperasian bagan petepete dimulai dengan menentukan daerah penangkapan (fishing ground). Penentuan fishing ground dilakukan dengan melihat pengalaman tahun-tahun sebelumnya, hasil tangkapan nelayan malam sebelumnya, dan hasil tangkapan nelayan lain. Penentuan fishing ground sepenuhnya ditentukan oleh juragan laut (Sulaiman 2006). Persiapan setelah penentuan fishing ground dilakukan yaitu: bahan bakar, pengecekan mesin, pemeriksaan lampu dan coldbox (styrofoam) beserta es balok dan garam. Konsumsi selama pengoperasian disediakan masingmasing, baik $A B K$ maupun punggawa laut. Bagan petepete menuju fishing ground yang telah ditentukan di fishing base. Jarak dari fishing base ke fishing ground bervariasi dari 3-11.50 mil. Lama waktu yang dibutuhkan ke fishing ground rata-rata sekitar 120 menit. Perbaikan waring dan tali temali dilakukan pada saat menuju fishing ground. Penurunan jangkar dan penyalaan lampu di fishing ground dilakukan setelah pengecekan dasar perairan. Dasar perairan sebaiknya berlumpur dan berada di belakang batu agar cahaya tidak memantul di permukaan batu serta alat tangkap terlindung dari arus yang kuat.

2. Proses penyalaan lampu. Lampu segera dinyalakan saat tiba di fishing ground dan telah dilakukan pengecekan dasar perairan. Lampu dinyalakan biasanya senja hari (pukul 18:00 WIT). Kondisi tertentu saat bagan belum sampai di fishing ground dan senja telah tiba, maka lampu yang dinyalakan hanya lampu tiang karena lampu merkuri bisa pecah jika menyala dan terkena hempasan air. Berbeda pada saat penelitian yang menggunakan lampu LED, lampu dapat dinyalakan dalam perjalanan karena lampu LED mempunyai pelindung yang kedap air. Penyalaan lampu ini kemungkinan dapat menarik perhatian ikan untuk mengikuti bagan sampai di fishing ground yang telah ditentukan.

3. Proses penurunan waring (setting). Setting dilakukan pada saat kondisi arus tidak terlalu kencang $\quad<0.15$ $\mathrm{m} / \mathrm{s}$ ) (Sudirman 2003). Tali pengikat waring bagian depan diikat di binkai bagan sebelum menurunkan badan waring. Kedua sisi waring diikat terlebih dahulu sebelum mengikat waring bagian belakang. Setelah semua ujung waring diikat, keempat batu arus yang berfungsi sebagai penahan waring dari arus agar waring membentuk persegi diturunkan terlebih dahulu sebelum bingkai waring. Bingkai bagan diturunkan secara perlahan untuk mencegah waring terpuntir ke atas dan terseret arus keluar dari atas bingkai bagan. Kedalaman bingkai bagan maksimal $20 \mathrm{~m}$. Proses setting adakalanya tidak dapat dilakukan walaupun ikan telah berkumpul di sekitar bagan karena ombak tinggi, arus dan angin terlalu kencang. Kondisi perairan seperti ini membuat nelayan menunggu sampai perairan kembali normal. Jika kondisi perairan semakin tidak bersahabat maka bagan segera berlindung di belakang pulau atau gusung.

4. Proses menunggu kawanan ikan (soaking). Lama proses soaking sangat tergantung cepat tidaknya ada kawanan ikan di sekitar bagan. Umumnya waktu soaking sekitar 220 menit. Kondisi ini sangat bergantung dari musim ikan, periode bulan dan keadaan cuaca. Ciri-ciri ikan telah berada di sekitar bagan atau pencahayaan yaitu: adanya gelembung-gelembung di dalam air (bentuk dan ukuran gelembung dapat dijadikan indikator jenis dan berapa besar kawanan ikan di dalam perairan), adanya kawanan ikan yang berenang secara teratur mengelilingi bagan, banyaknya kawanan cumi-cumi yang nampak di permukaan dan warna 
perairan yang agak gelap dikarenakan kawanan ikan yang berada di sekitar pencahayaan.

5. Proses pemadaman lampu. Proses pemadaman lampu dilakukan sangat tergantung dari ada tidaknya ikan yang berkumpul di sekitar bagan. Pemadaman lampu bahkan tidak dilakukan sampai 8 jam apabila kondisi perairan tidak memungkinkan dilakukan setting karena arus dan angin teramat kencang sehingga waring nampak di permukaan, gelombang yang besar sehingga dapat mengakibatkan keseimbangan kapal terganggu, dan hujan yang sangat lebat yang membuat batas pandang sangat terbatas. Pemadaman lampu dilakukan secara bertahap untuk menggiring ikan masuk di catchable area. Lampu pertama yang dipadamkan adalah lampu yang berada pada bagian terluar rangka bagan dan lampu tiang yang arah pencahayaannya berfungsi menarik ikan yang jauh agar mendekati bagan. Pemadaman lampu di bawah rangka bagan juga dilakukan secara bertahap, mulai deretan terluar rangka bagan, sehingga kawanan ikan diharapkan semakin terkonsentrasi di catchable area. Pada akhirnya hanya lampu fokus yang menyala dan diredupkan secara perlahan selama 10-15 menit (peredupan dilaksanakan jika yang terkonsentarsi ikan layang dan teri hitam, jika ikan teri putih maka peredupan lampu fokus tidak terlalu redup).

6. Proses pengangkatan waring (hauling). Hauling dimulai setelah juragan mengamati secara visual kawanan ikan yang telah bergerombol di bawah rangkan bagan dan bergerak teratur mngelilingi bagan. Juragan laut memberikan isyarat bahwa waring segera ditarik. Pemutaran roller waring dilakukan dengan cepat agar kawanan ikan di catchable area tidak meloloskan diri. Saat pemutaran roller waring, tali jangkar juga dikendorkan agar bingkai waring berada tepat di bawah rangka bagan saat penarikan bingkai waring. Waktu yang dibutuhkan menarik bingkai waring sampai ke rangka bagan bergantung pada kecepatan arus dan kedalaman bingkai waring. Umumnya lama penarikan waring berkisar 12.50 menit. Kondisi perairan yang arah arus dan angin berbeda mengakibatkan posisi bingkai waring berada di sisi bagan, maka perlu pengaturan antara tali jangkar dengan tali bantu jangkar agar posisi bingaki waring tepat di bawah rangka bagan. Tali bantu jangkar di bawah ke depan ujung bagan (kiri atau kanan) tergantung ke arah mana haluan bagan diarahkan. Sebagai contoh bingkai bagan berada di sisi kanan bagan, maka tali bantu jangkar ditempatkan di depan bagian kanan bagan. Sambil mengendurkan tali jangkar, tali bantu jangkar ditahan yang mengakibatkan bagian belakang bagan akan mengarah ke kanan sehingga bingkai waring tepat di bawah rangka bagan.

7. Pengambilan hasil tangkapan. Proses selanjutnya adalah menggiring ikan ke bagian sisi waring yang berfungsi sebagai kantong setelah bingkai waring ditarik sampai ke rangka bagan dan lampu dinyalakan kembali. Ikan tidak dapat meloloskan diri setelah bingkai waring terikat di rangka bagan. Waring bagian depan diangkat sampai tepat di bawah linggi kapal, demikian pula bagian belakang ditarik tepat di bawah propeller. Waring sebelah kanan diangkat sampai bagian kantong dan waring sebelah kiri diangkat sampai rapat ke badan perahu bagan, selanjutnya waring ditarik sedemikian rupa melewati bagian bawah perahu bagan sampai disisi kanan perahu sehingga terbentuk kantong sehingga ikan tergiring sampai di kantong waring. Jika ikan sudah terkumpul, ikan diangkat ke atas perahu dengan menggunakan serok dilanjutkan dengan penyortiran. Ikan yang sejenis dikelompokkan ke dalam satu basket dan dimasukkan ke dalam peti styrofoam setelah dicampur es atau garam. Pada saat ini pula tali jangkar ditarik kembali, waring diturunkan untuk melakukan proses penangkapan berikutnya.

8. Proses pengangkatan waring ke atas bagan. Proses pengangkatan waring dilakukan jika ingin pindah fishing ground, berlindung, atau kembali ke fishing base. Tali pengikat waring bagian depan dilepaskan dari bingaki waring. Waring bagian depan dimasukkan di bagian bawah sebelah kanan rangka bagan dan ditarik dengan roller waring yang berada di sisi kiri rangka bagan. Semua tali pengikat waring dilepas dan waring ditarik dengan roller waring sedikit demi sedikit sampai keseluruhan waring berada di atas bagan.

Pengetahuan metode pengoperasian bagan petepete dalam hubungannya dengan 
perbaikan teknik dan metode penangkapan ikan merupakan salah satu faktor yang berkaitan dengan upaya pengembangan operasi penangkapan ikan yang lebih efisien dan efektif. Hal-hal yang perlu diperhatikan dalam perbaikan teknik dan metode penangkapan pada bagan pete pete saat ini adalah:

1. Kedalaman bingkai waring perlu diperhatikan agar tepat berada di bawah kawanan ikan. Penentuan kedalaman waring sangat tergantung jenis ikan, musim dan waktu hauling, sehingga sangat dibutuhkan pengalaman dan alat bantu untuk mendeteksi keberadaan ikan di perairan seperti peralatan akustik. Kedalaman bingkai waring jika pada musim ikan teri dan kembung sebaiknya pada kedalaman $15 \mathrm{~m}$ dikarenakan jenis ikan ini adalah ikan yang bergerombol dekat permukan air, tidak seperti halnya kawanan ikan layang yang tersusun seperti pita dan berada sampai kedalaman $30 \mathrm{~m}$.

2. Teknik pemadaman lampu juga perlu diperhatikan agar kawanan ikan tetap berada di atas bingkai waring. Penggunaan intensitas yang tinggi digunakan jika kawanan ikan adalah ikan teri putih dan kembung karena jenis ikan ini menyenangi intensitas cahaya yang tinggi, sedangkan kawanan ikan layang dan teri hitam menyenangi intensitas cahaya yang rendah.

3. Penempatan dan sudut pancaran lampu LED perlu diperhatikan agar ikan dapat di Tarik dari jauh dan tidak berada di bawah waring karena sifat lampu LED yang fokus dan mempunyai intensitas cahaya yang lebih dalam dan jauh.

4. Waktu hauling sebaiknya dilakukan sebelum dan sesudah tengah malam karena sebelum tengah malam merupakan waktu dimana ikan yang menyenangi cahaya terang sudah teradaptasi sempurna, sedangkan setelah tengah malam merupakan waktu dimana ikan yang tidak menyenangi cahaya terang teradaptasi sempurna.

5. Penggunaan mesin alat pemutar roller sudah sangat dibutuhkan karena dapat mengurangi tenaga ABK yang semakin hari sulit untuk didapat juga untuk mengurangi proses terjadinya pengangkatan waring yang tidak bersamaan. Pengangkatan bing-kai waring yang tidak bersamaan dapat menyebabkan bingkai waring patah. Pengangkatan waring secara manual yang selama ini diterapkan nelayan terjadi karena kekuatan memutar setiap ABK berbeda-beda.

6. Penggunaan peralatan navigasi seperti GPS dan fish finderuntuk mempermudah penentuan lokasi penangkapan dan mendeteksi kawanan ikan.

Secara singkat proses penangkapan ikan pada bagan petepete dapat dilihat pada Gambar 3 dan waktu yang dibutuhkan untuk setiap kegiatan dalam operasi Bagan petepete dapat dilihat pada Tabel 1 .

\section{Tingkah laku ikan di sekitar pencahayaan}

Pengamatan secara visual hanya diamati sampai kedalaman $2 \mathrm{~m}$. Ikan masuk ke daerah pencayahaan di bawah rangka bagan setelah 5-10 menit. Jenis ikan yang pertama masuk adalah ikan yang sangat kecil yang tidak teridentifikasi disusul dengan ikan teri, cumi-cumi, dan ikan terbang. Ikan kecil yang tidak teridentifikasi bergerak tidak beraturan. Terkadang ikan tersebut berputar berlawanan arah jarum jam dan kadang tersebar jika ada ikan yang berukuran lebih besar.

Ikan teri yang nampak di permukaan masih dalam kawanan yang sangat kecil. Pola kedatangan kawanan ini sesekali muncul kemudian menjauh dari sumber pencahayaan. Cumi-cumi mendatangi sumber pencahayaan dengan pergerakan naik turun mendatangi ikan-ikan yang berkumpul di sekitar pencahayaan yang berada dekat lambung kapal sedangkan lampu yang berada jauh dari lambung kapal tidak nampak ikan kecil yang berkelompok di bawah lampu.

Pengamatan tingkah laku ikan pada kedalaman lebih dari $2 \mathrm{~m}$ diamati dengan menggunakan GPS Map Sounder Plotter. Hasil tampilan display fish finder menunjukkan bahwa ikan mulai mendekati bagan setelah 10-20 menit lampu dinyalakan. Ikan mendatangi sumber pencahayaan pada kedalaman yang bervariasi. Ikan yang datang mendekati sumber cahaya pada kedalaman di 0-20 m kemungkinan adalah ikan yang berfototaksis positif sedangkan ikan yang mendatangi sumber pencahayaan pada kedalaman 20-40 m adalah ikan yang mendatangi sumber cahaya karena mencari makan atau ikan yang menyenangi cahaya yang tidak terlalu terang (Gambar 4). Diperkirakan ikan yang mendatangi sumber cahaya pada kedalaman 0-20 m adalah ikan teri, tembang dan kembung sedangkan pada kedalaman lebih dari $20 \mathrm{~m}$ adalah ikan 
layang, peperek dan barakuda.

Gambar 4a memperlihatkan bahwa ikan yang mendatangi bagan jumlahnya masih sedikit dan terus bertambah seiring bertambahnya waktu penyinaran. Gambar 4a, 4b, 4c (sekitar 150 menit) ikan masih berada di kisaran kedalaman 20-40 m. Hal ini dikarenakan lampu yang digunakan masih dinyalakan semua sehingga ikan masih cenderung berkumpul di kedalaman tersebut. Gambar 4d, 4e dan 4f ikan sebagian besar sudah berkumpul di kedalaman 0-20 m. Hal ini dikarenakan ikan lampu sudah mulai dipadamkan secara bertahap sehingga ikan cenderung mengikuti iluminasi cahaya yang disenanginya. Tampak pada Gambar 4f ikan sudah mulai berkumpul di permukaan karena pada saat ini hanya lampu fokus yang dinyalakan. Menurut Arimoto et al. (2011), perbedaan-perbedaan dalam pengaturan lampu dianggap menggambarkan perilaku ikan dan alasan mengapa ikan tertarik kepada cahaya yaitu: bergerombol untuk mencari makan, respon terkondisi dengan intensitas cahaya tinggi, perilaku keingintahuan dan perilaku sosial lainnya, fototaksis positif membuat ikan berorientasi ke sumber cahaya, intensitas cahaya optimum untuk mencari makan dan kegiatan lainnya, dan disorientasi dan imobilisasi karena tingkat cahaya yang tinggi dan di sekitarnya kondisi gelap. Reaksi ikan inilah yang dimanfaatkan untuk menangkap ikan dengan mengunakan alat bantu cahaya, sehingga pergerakan ikan semakin ke permukaan dan masuk ke dalam area tangkapan alat tangkap yang digunakan.

Tabel 1. Rata-rata waktu yang dibutuhkan pada masing-masing aktivitas operasi Bagan pete pete di Perairan Barru Selat Makassar Sulawesi Selatan

\begin{tabular}{clc}
\hline No. & \multicolumn{1}{c}{ Deskripsi } & Waktu yang dibutuhkan (menit) \\
\hline 1. & Menuju fishing ground & 120 \\
2. & Persiapan setting & 15 \\
3. & Setting & 7.50 \\
4. & Pencahayaan & 220 \\
5. Pemadaman lampu secara & 45 \\
berkala & 12.50 \\
6. Hauling & 12.50 \\
7. & Menggiring ikan ke sisi \\
perahu & 50 \\
8. & Mengangkathasil tangkapan & 100 \\
ke atas perahu & 120 \\
9. Penyortiran hasil tangkapan & \\
10. Kembali ke fishing base &
\end{tabular}




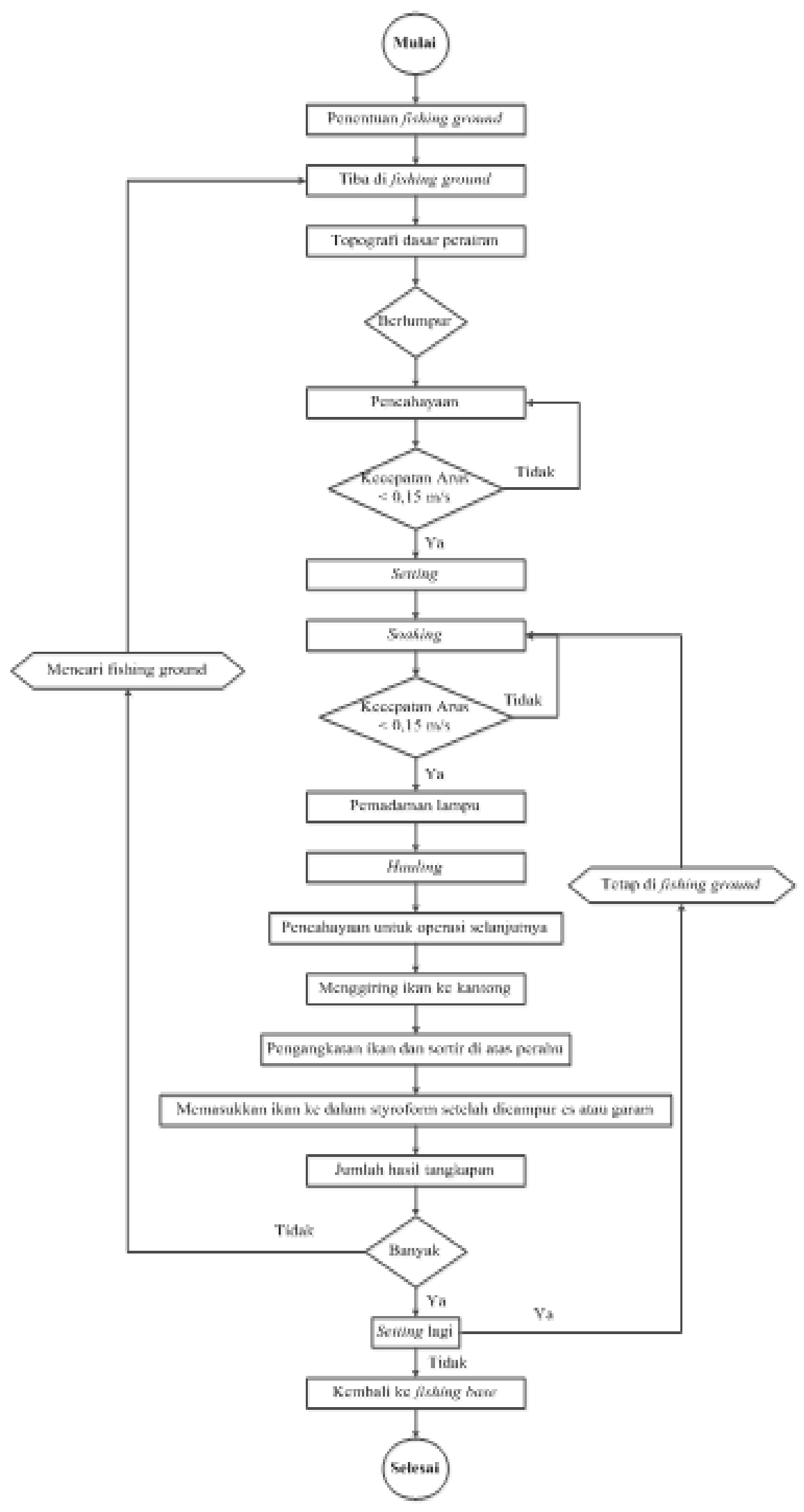

Gambar 3. Proses operasi penangkapan ikan pada bagan pete pete 


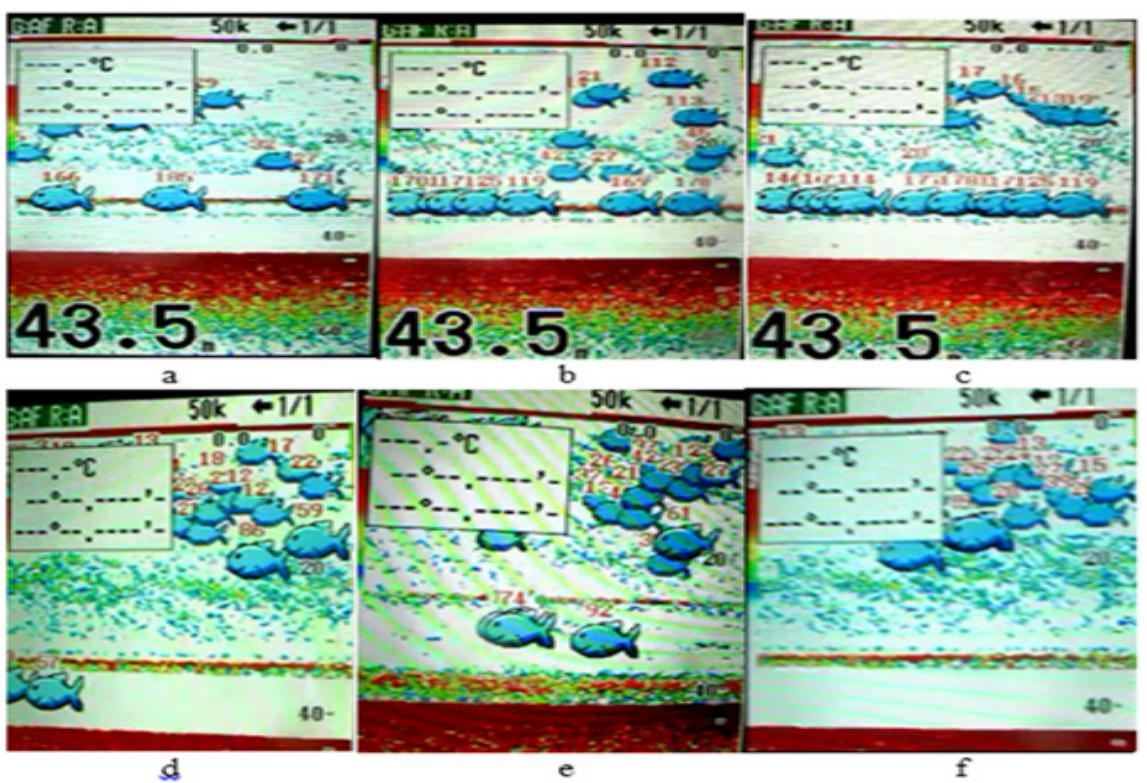

Gambar 4. Tampilan GPS Map Sounder Plotter pada saat dilakukan operasi penangkapan

\section{KESIMPULAN DAN SARAN}

\section{Kesimpulan}

Waktu yang dibutuhkan untuk setiap proses penangkapan adalah: setting ratarata 7.50 menit, pencahayaan rata-rata 220 menit, pemadaman lampu secara berkala rata-rata 45 menit, hauling rata-rata 12.50 menit, menggiring ikan ke sisi perahu ratarata 12.50 menit dan mengangkat hasil tangkapan ke atas perahu rata-rata 50 menit. Teknik pemadaman lampu perlu mendapat perhatian khusus agar kawanan ikan tetap berada di bawah area bingkai waring. Hauling harus memperhatikan arus dan angin hubungannnya dengan keberadaan binkai jaring yang harus tepat berada di bawah rangka bagan.

Pola pergerakan kawanan ikan mendatangi pencahayaan berada pada kedalaman 5-10 m dan 20-40 m dari segala arah pada saat semua lampu dinyalakan dan terus menuju permukaan seiring pemadaman lampu secara bertahap. Pola Kawanan ikan terkonsentrasi di sekitar catchable area pada saat hanya satu lampu yang dinyalakan di setiap sisi dengan kawanan semakin sedikit tetapi kepadatan kawanan yang besar.

\section{Saran}

Pengembangan alat tangkap bagan petepete dengan menggunakan lampu LED masih memerlukan penelitian lanjutan tentang perbedaan warna maupun kelimpahan plankton dan produktivitas perairan di sekitar pencahayaan.

\section{UCAPAN TERIMA KASIH}

Kami sangat berterima kasih kepada H. Amal pemilik bagan pete pete, nahkoda dan anak buah kapal "putra Bahari" untuk kerjasamanya selama penelitian. Penelitian ini dibiayai oleh Ditjen Dikti melalui bantuan penelitian Hibah Bersaing Tahun Anggaran 2014.

\section{DAFTAR PUSTAKA}

Arimoto T, Glass CW, Zhang X. 2011. Fish Vision and Its Role in Fish Capture. In: Pingguo $\mathrm{He}$ (ed). Behaviour of Marine Fish: Capture Processes \& Conservation Challenges.

Hua LT, Xing J. 2013. Research on LED Fishing Light. Research Journal of Applied Sciences, Engineering and Technology. 5(16):4138-4141

Inada $\mathrm{H}$, Sato $\mathrm{K}$, Inoue $\mathrm{T}$, Mino $\mathrm{T}$, Sano E. 2010. LED application for ecoharmonic light fishing. The Energy Use in Fisheries Symposium: Improving Efficiency and Technological Innovations from a Global Perspective. Washington: Sheraton Hotel Seattle.

Martasuganda S. 2006. Pendekatan akustik dalam studi tingkah laku ikan pada proses penangkapan dengan alat bantu cahaya [Tesis]. Bogor: Institut 
Pertanian Bogor.

Okamoto T, Takahashi K, Ohsawa H, Fukuchi K, Hosogane K, Kobayashi S, Moniwa M, Sasa K, Yoshino H, Ishikawa $\mathrm{H}$, Harada $\mathrm{M}$, Asakura M, Ishii H. 2008. Application of LEDS to Fishing lights for pacific saury. $J$. Light \& Vis. Env. 32(2):38-42.

Sato $\mathrm{K}$, Inada $\mathrm{H}$, Sakamoto $\mathrm{Y}$, Uchida $\mathrm{H}$, Tsuda S. 2010. Trial operation of LED fishing light for squid jigging. The Energy Use in Fisheries Symposium: Improving Efficiency and Technological Innovations from a Global Perspective. Washington: Sheraton Hotel Seattle.

Sudirman. 2003. Analisis tingkah laku ikan untuk mewujudkan teknologi ramah lingkungan dalam proses penangkapan pada bagan rambo
[Disertasi]. Bogor: Institut Pertanian Bogor.

Toeda H, Inada H, Ozawa K. 2010. Practicable LED fishing light for saury lift net. The Energy Use in Fisheries Symposium: Improving Efficiency and Technological Innovations from a Global Perspective. Washington: Sheraton Hotel Seattle.

Yamashita Y, Matsushita Y, Azuno T. 2012. Catch performance of coastal squid jigging boats using LED panels in combination with metal halide lamps. Fisheries Research. 113(1):182-189.

Von Brand A. 2005. Fish Catching Methods of the World. $4^{\text {th }}$ edition. in Gabriel $\mathrm{O}$, Lange $\mathrm{K}$, Dahm L, Wendt $\mathrm{T}$ (ed). England: Blackwell Publishing Ltd. 